Check for updates

Cite this: RSC Adv., 2020, 10, 9730

\title{
Stereoselective synthesis of (+)-5-thiosucrose and (+)-5-thioisosucrose $\uparrow$
}

\author{
Atsushi Ueda, (D) *ab Jinhong $\mathrm{Pi}^{\text {a }}{ }^{\text {Yui Makura, }}{ }^{\mathrm{b}}$ Masakazu Tanaka ${ }^{\mathrm{b}}$ \\ and Jun'ichi Uenishi ${ }^{* a c}$
}

(+)-5-Thiosucrose 1, a novel isosteric sulfur analog of sucrose, was synthesized stereoselectively for the first time via indirect $\beta$-D-fructofuranosidation involving selective $\beta$-D-psicofuranosidation, followed by stereoinversion of the secondary hydroxy group at the $\mathrm{C}-3$ position on the furanose ring. Glycosidation of protected 5-thio-D-glucose with a D-psicofuranosyl donor provided $\beta$-D-psicofuranosyl 5-thio- $\alpha$-Dglucopyranoside and that with $D$-fructofuranosyl donor gave $\alpha$-D-fructofuranosyl 5-thio- $\alpha$-Dglucopyranoside. Two anomeric stereocenters of the glycosyl donor and acceptor were controlled correctly to provide a single disaccharide among four possible anomeric isomers in the glycosylation. Conversion of the resulting disaccharides afforded (+)-5-thiosucrose 1 and (+)-5-thioisosucrose 2 in excellent yields, respectively. Inhibitory activities of 1 and 2 against $\alpha$-glucosidase in vitro were also examined.

Received 3rd February 2020

Accepted 28th February 2020

DOI: 10.1039/d0ra01033b

rsc.li/rsc-advances

\section{Introduction}

Sucrose (Fig. 1) is one of the common sugars in nature and is an important carbohydrate for energy source in human health. At the same time, it is also a favorite sweetener in our daily life. So far, a variety of synthetic analogs of sucrose have been synthesized as low- or noncalorie alternatives for a healthy dietary
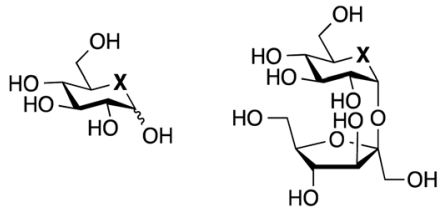

$\begin{array}{ll}\text { D-Glucose } & (+) \text {-Sucrose } \\ X=O & X=O \\ \text { 5-Thio-D-glucose } & \text { 5-Thiosucrose (1) } \\ X=S & X=S\end{array}$

Fig. 1 Structures of glucose, sucrose, isosucrose, and their sulfur analogs.

\footnotetext{
${ }^{a}$ Kyoto Pharmaceutical University, Misasagi, Yamashina, Kyoto 607-8412, Japan. E-mail:aueda@nagasaki-u.ac.jp; juenishi@phs.osaka-u.ac.jp

${ }^{b}$ Graduate School of Biomedical Sciences, Nagasaki University, 1-14 Bunkyo-machi, Nagasaki 852-8521, Japan

'Graduate School of Pharmaceutical Sciences, Osaka University, Suita, Osaka 5650871, Japan

$\uparrow$ Electronic supplementary information (ESI) available: Experimental details, copies of ${ }^{1} \mathrm{H},{ }^{13} \mathrm{C}$, and gCOSY NMR spectra. See DOI: 10.1039/d0ra01033b
}

purpose. For example, sucralose (Splenda ${ }^{\circledR}$ ) is a widely known analog of sucrose in which three hydroxy groups are replaced by chlorine atoms, leading to a hundredfold increase in sweetness compared to that of sucrose. ${ }^{1}$ Many other derivatives of sucrose with different substituents have also been reported. ${ }^{2}$ However sucrose analogs in which an atom in the sucrose ring system is changed are far less common. As rare examples, C-sucrose, in which the glycosidic oxygen is replaced by a carbon atom, was synthesized by Kishi et al., and hemicarbasucrose, a carbaanalog of sucrose, was reported by Jiménez-Barbero and Sollogoub et al..$^{3}$ Although sucrose is an actual substrate for $\alpha$ glucosidase, these modified sucrose analogs are not substrates of $\alpha$-glycosidase and non-notable activities in inhibition against $\alpha$-glycosidase were reported.

Thiosugars replace a ring oxygen atom with a sulfur atom in carbohydrate, and are extremely rare in nature with the exception of 5-thio-D-mannose ${ }^{4}$ and salacinols. ${ }^{5}$ It should be noted that salacinol has potent enzymatic inhibitory activity against $\alpha$ glucosidase. In fact, it has been already approved and used commercially in the context of dietary drinks or supplement of foods. Hetero monosaccharides, including thiosugars, ${ }^{6}$ azasugars, ${ }^{7}$ and carbasugars, ${ }^{8}$ and their disaccharide analogs ${ }^{9}$ have been synthesized as sugar mimics and their biological behaviors and functions involving $\alpha$-glucosidase inhibitory activity were examined. ${ }^{10}$ However, there has been nothing potent beyond salacinol concerning $\alpha$-glucosidase inhibition. ${ }^{11,12}$

$\alpha$-Glucosidase hydrolyzes sucrose to fructose and glucose, and interestingly, 5-thio-D-glucose inhibits this process. ${ }^{11 a_{f} f} \mathrm{~A}$ pyranose ring oxygen is essentially required for the substrates of $\alpha$-glucosidase. ${ }^{13}$ As an isosteric analog of sucrose, 5 -thiosucrose 1 and 5-thioisosucrose 2 possesses a 5 -thioglucose moiety and 
would resemble the conformation of sucrose. We thought that 1 would be of interest as a sweetener as well as an inhibitor superior than 5-thio-D-glucose. This research is focused on the stereoselective synthesis of 5-thiosucrose 1 and 5-thioisosucrose 2 , and herein we report their synthesis and some biological properties.

\section{Results and discussion}

Although many methods for the stereoselective glycosylation have been reported and utilized, ${ }^{\mathbf{1 4}}$ early attempts at the synthesis of sucrose ${ }^{15}$ revealed the difficulties involved with the stereocontrol of its two anomeric centers. For the synthesis of 1 and 2 , two anomeric carbon centers connected with $\beta, \alpha$ - and $\alpha, \alpha$-O-linkage $[1 ; \quad \beta$-D-Fruf- $(2 \leftrightarrow 1)-\alpha$-D-Glc $p$ and $2 ; \alpha$-D-Fruf$(2 \leftrightarrow 1)-\alpha$-D-Glc $p]$ need to be controlled in a glycosylation step. An $\alpha$-selectivity rather than $\beta$-selectivity was reported for glycosidation of D-fructose as an either glycosyl acceptor or donor. ${ }^{\mathbf{1 4 a}}$ In fact, glycosidation of D-fructofuranose affords an $\alpha$-anomer or $\alpha$-predominant mixtures in most cases. ${ }^{16}$ On the other hand, 5 -thio-D-glucose has been used as a glycosyl donor to form an $\alpha$ glycosidic bond by the anomeric effect of the sulfur ring. ${ }^{6}$ However, it has never been used as an acceptor in glycosidation reaction to our best knowledge.

Despite these failures in $\beta$-D-fructofuranosidation, the natural occurrence of $\beta$-D-furanoside can be found in sucrose and inulin. Therefore, $\beta$-directing $\mathrm{D}$-fructofuranosylation has been a challenging task and this has encouraged carbohydrate chemists to develop selective $\beta$-D-fructofuranosylation. There is only one elegant example in $\beta$-D-fructofuranosylation, reported by Oscarson et al. ${ }^{17}$ As shown in Scheme 1, they used ethyl thioglycoside 3 as a D-fructofuranosyl donor, in which the C-1 and C-4 hydroxy groups are fixed with a connection of cyclic disiloxyether to block an attack from the $\alpha$-face of the furanose ring. Stereoselective glycosylation of the acceptor 4 with 3 promoted by dimethyl(methylthio)sulfonium triflate (DMTST) in the presence of 2,6-di-tert-butyl-4-methylpyridine (DTBMP) and $4 \AA$ molecular sieves occurred to give $\beta$-furanosyl $\alpha$-pyranoside 5 with $68 \%$ yield, exclusively. ${ }^{17 a}$

Accordingly, we initially attempted the Oscarson's method for the synthesis of $\mathbf{1}$. However, glycosidation of 2,3,4,6-tetra-Obenzyl-5-thio-D-glucopyranose $(\mathbf{6})^{18}$ with 3 gave no desired disaccharide. Instead, disulfide 7 was isolated in $88 \%$ yield. Activation of sulfide by DMTST occurred on the endo-sulfide of the acceptor 6 instead of the exo-sulfide of the donor 3. Therefore, this method could be useful for general oxygen sugars but not for thiosugars.

Since Oscarson's $\beta$-D-fructofuranosylation method was found to be incompatible with the synthesis of $\mathbf{1}$, we turned our attention to indirect synthesis through $\beta$-D-psicofuranosylation, which was employed in the stereoselective synthesis of sucrose previously. ${ }^{19}$ We have reported that glycosidation of D-glucopyranose with D-psicofuranosyl donor ${ }^{20}$ protecting 3,4-diols with acetonide gave $\beta$-D-psicofuranosyl $\alpha$-D-glucopyranoside, which afforded sucrose after several steps. D-Psicofuranosyl donor was regarded as $\beta$-D-fructofuranosyl donor in the disaccharide syntheses. ${ }^{19,21}$ On the other hand, glycosylation of $\mathrm{D}^{-}$

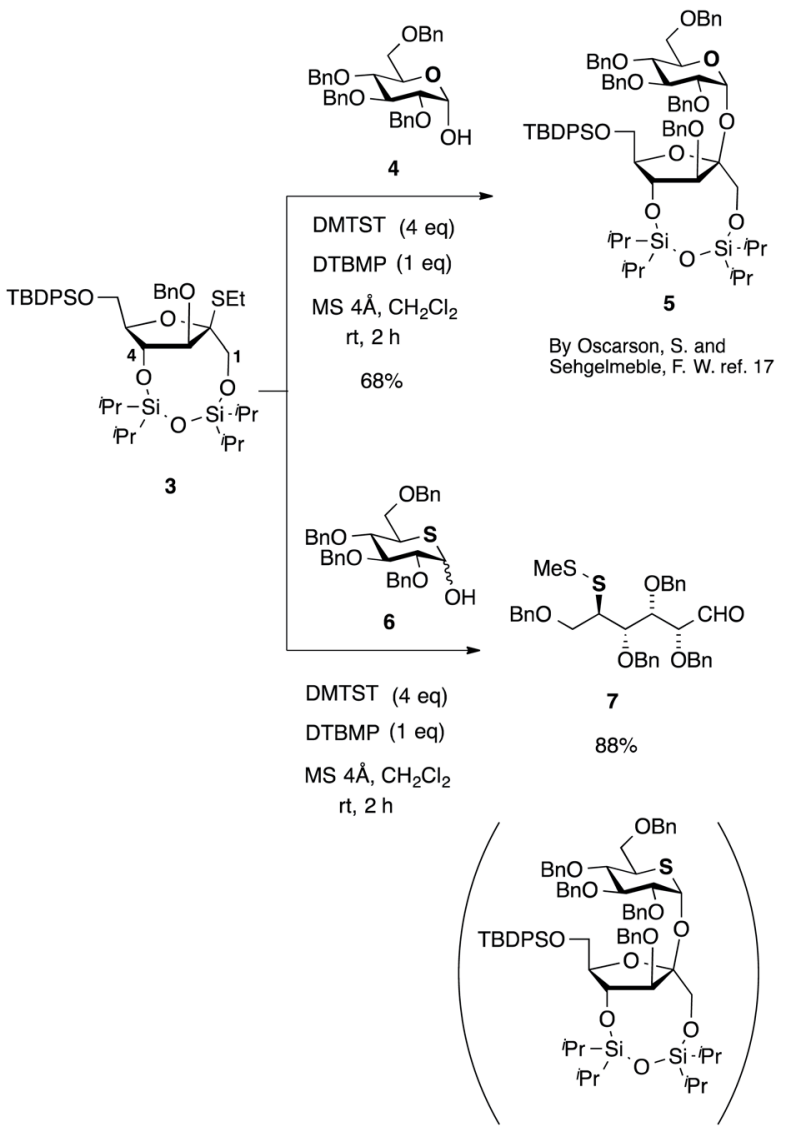

Scheme 1 Reaction of Oscarson's glycosyl donor 3 with acceptors 4 and 6 .

glucopyranose with $\mathrm{D}$-fructofuranosyl donor occurred to give $\alpha$ D-fructofuranosyl $\alpha$-D-glucopyranoside predominantly which was used for the synthesis of isosucrose. The course of $\alpha$-Dfructofuranosylation or $\beta$-D-psicofuranosylation could be governed by the stereochemistry of the C-3 hydroxy substituent. Glycosidation of acceptor with D-fructofuranosyl donor is not sufficient for the syntheses of $\beta$-D-fructofuranosides, but is suitable for $\alpha$-D-fructofuranoside. Based on the above results, synthetic plan for $\mathbf{1}$ and $\mathbf{2}$ is depicted in Fig. 2 .

D-Fructofuranosyl donor with 5-thioglucose acceptor would give $\alpha$-D-fructofuranosyl 5 -thio- $\alpha$-D-glucopyranoside, of which anomeric centers would matched with the stereochemistry of 2 . Glycosylation of 5-thioglucose acceptor with D-psicofuranosyl donor would give $\beta$-D-psicofuranosyl 5 -thio- $\alpha$-D-glucopyranoside of which anomeric centers would matched with the stereochemistry of $\mathbf{1}$. This disaccharide will lead to $\mathbf{1}$ after a stereoinversion at the C-3 hydroxy group. In both cases, $\alpha$-glycoside on the anomeric center of 5-thioglucopyranose would be formed by the strong anomeric effect of the thiane ring.

\section{Synthesis of 5-thioisosucrose (2)}

Several D-fructofuranosyl donors are available. Fructofuranosyl halide, ${ }^{16 a}$ fructofuranosyl phosphite, ${ }^{\mathbf{1 6 c}}$ 2-O-acetylfructofuranose, ${ }^{16 e}$ 2-thiofructofuranoside, ${ }^{16 d}$ and fructofuranosyl $\mathrm{N}$-phenyltrifluoroacetimidate ${ }^{\mathbf{1 6 f}}$ have been reported. Nevertheless, 


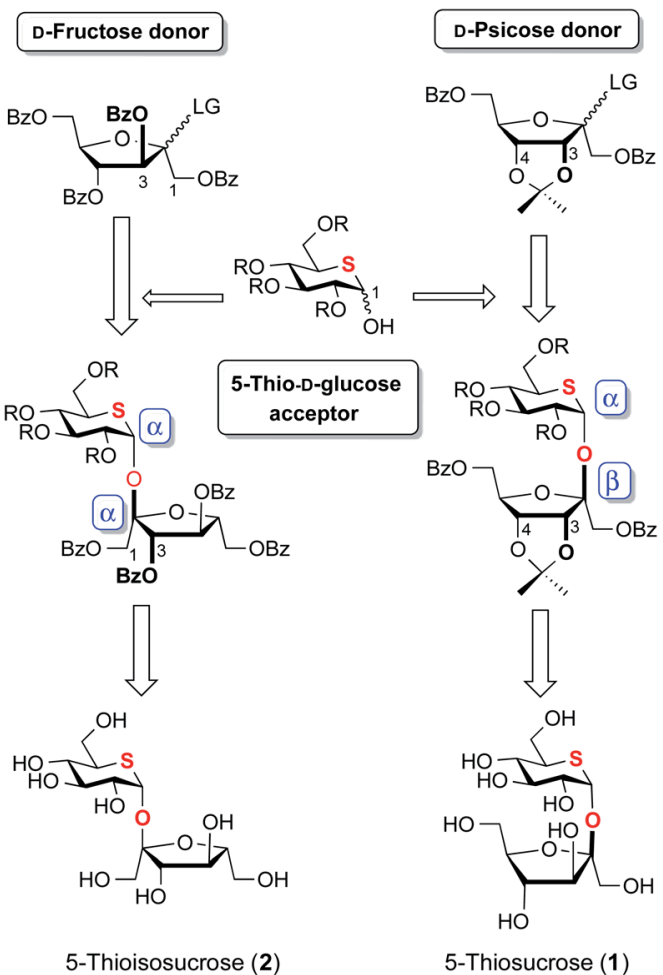

Fig. 2 Synthetic plan for 5-thiosucrose 1 and 5-thioisosucrose 2.

most of these glycosidations entail synthetic difficulties since Dfructose possesses a sterically congested anomeric hydroxy group due to the structure of ketohexofuranose. In addition, the choice of leaving groups is restricted in this case because a sensitive cyclic sulfide unit exists in the glycosyl acceptor for the synthesis of 2.

As shown in Scheme 2, we examined three different D-fructofuranosyl donors, thus imidate donor ${ }^{22} \mathbf{8 b}$, phosphite donor $\mathbf{8 c},{ }^{16 c}$ and benzyl phthalate donor ${ }^{23}$ 8d. These donors were prepared from 1,3,4,6-tetra-O-benzoyl-D-fructofuranose (8a). ${ }^{16 b}$ Trimethylsilyl trifluoromethanesulfonate (TMSOTf) promoted glycosylation of 2,3,4,6-tetra-O-acetyl-5-thio-D-glucose 9 (ref. 18)

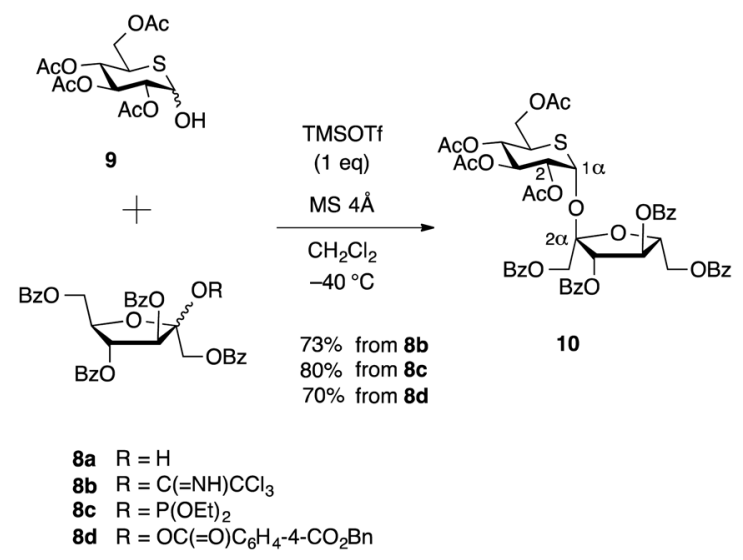

Scheme $2 \alpha$-D-Fructofuranosylation of 5-thio-D-glucopyranose 9. with each glycosyl donor $\mathbf{8 b}, \mathbf{8 c}$, or $\mathbf{8} \mathbf{d}^{24}$ at $-40{ }^{\circ} \mathrm{C}$ in dichloromethane in the presence of $4 \AA$ molecular sieves resulted in the formation of $2 \alpha, 1 \alpha$-disaccharide 10 [ $\alpha$-D-Fruf- $(2 \leftrightarrow 1)-\alpha$-D-Glc $p$ ] as a single isomer with $73 \%, 80 \%$, and $70 \%$ yields, respectively. It is noteworthy that a single isomer $(2 \alpha, 1 \alpha)$ was formed exclusively among the four possible anomeric isomers $(2 \beta, 1 \alpha, 2 \alpha, 1 \alpha$, $2 \alpha, 1 \beta$, and $2 \beta, 1 \beta)$ in this glycosidation, while D-glucopyranosyl acceptor reported in the synthesis of isosucrose produced two anomeric isomers $(2 \alpha, 1 \alpha, 2 \alpha, 1 \beta)$ in moderate selectivities $\left(47: 53,{ }^{16 a} 4: 1{ }^{16 c}\right.$ and $84: 16$ (ref. 16e)). Although the three fructofuranosyl donors used in this study showed similar reactivity and selectivity, phthalate donor $\mathbf{8 d}$ is regarded as the most convenient donor because it is readily prepared and stable under storage, in comparison with other donors $\mathbf{8 b}$ and $\mathbf{8 c}$.

Stereochemistry at the anomeric positions in $\mathbf{1 0}$ was determined by the coupling constant in the ${ }^{1} \mathrm{H}$ NMR spectrum and the chemical shifts in the ${ }^{13} \mathrm{C}\left\{{ }^{1} \mathrm{H}\right\}$ NMR spectrum. The $J_{1,2}$ value of the pyranose ring proton is $3.1 \mathrm{~Hz}$, which is in the typical value of $\alpha$-glucopyranoside, and it is identical to that of $1,2-c i s-\alpha$ D-glucopyranoside. The ${ }^{13} \mathrm{C}\left\{{ }^{1} \mathrm{H}\right\}$ NMR chemical shift of the anomeric position of the furanose ring exhibits at $109.0 \mathrm{ppm}$, which is identified to that of $\alpha$-D-fructofuranoside. ${ }^{17 a, 25}$ These data supported the structure of the disaccharide $\mathbf{1 0 .}$

Finally, treatment of $\mathbf{1 0}$ with $\mathrm{NaOMe}$ in $\mathrm{MeOH}$ furnished the synthesis of 2 in $90 \%$ yield (Scheme 3). Compound 2 was synthesized in two steps from $\mathrm{D}$-fructose donor with strict stereocontrol of two anomeric centers. The corresponding octaacetate 11 was prepared in $89 \%$ yield in order to compare the analytical data with the related disaccharides shown in Table 1.

\section{Synthesis of 5-thiosucrose (1)}

According to the synthetic plan, we started the synthesis of 1 through $\beta$-D-psicofuranosidation. The initial step of this synthesis involved $\beta$-selective glycosidation of 6 with the Oprotected D-psicofuranosyl donor $12,{ }^{18,19,24}$ which was prepared from D-psicose in $49 \%$ overall yield in five steps. ${ }^{20 b}$ Reaction of 6 with 12 in the presence of TMSOTf in dichloromethane at -40 to $-20{ }^{\circ} \mathrm{C}$ afforded the desired glycoside 13 in $76 \%$ yield as a single stereoisomer (Scheme 4). The configuration of the anomeric center on the pyranoside ring in $\mathbf{1 3}$ was identified as that of $\alpha$-D-glucopyranoside by a $J_{1,2}$ value of $2.9 \mathrm{~Hz}$. The anomeric center in D-psicofuranoside was identical to $\beta$ -
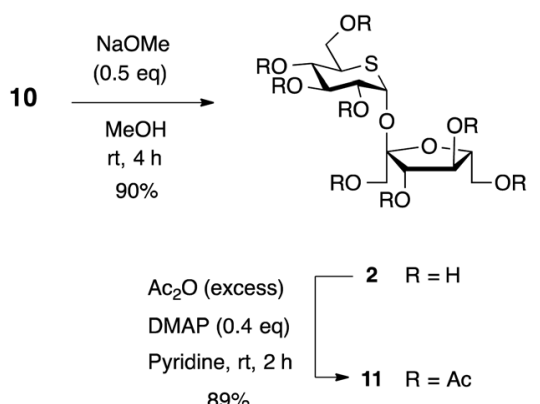

Scheme 3 Synthesis of 5-thioisosucrose 2 and its acetate 11. 
Table 1 Comparison of octaacetyl disaccharides 18, 11, 19, and 20

\begin{tabular}{|c|c|c|c|c|c|c|c|c|c|c|c|c|}
\hline \multirow[b]{2}{*}{ Compound } & \multirow{2}{*}{$\frac{\text { Specific rotation }^{a}}{[\alpha]_{\mathrm{D}}}$} & \multicolumn{7}{|c|}{ Chemical shifts of furanose protons ${ }^{b}(\delta)$} & \multicolumn{4}{|c|}{$\begin{array}{l}\text { Coupling constants of furanose } \\
\text { protons }^{b}(\mathrm{~Hz})\end{array}$} \\
\hline & & $\mathrm{H}-1 \mathrm{a}$ & $\mathrm{H}-1 \mathrm{~b}$ & $\mathrm{H}-3$ & $\mathrm{H}-4$ & $\mathrm{H}-5$ & H-6a & $\mathrm{H}-6 \mathrm{~b}$ & $J_{3,4}$ & $J_{4,5}$ & $J_{5,6 \mathrm{a}}$ & $J_{5,6 \mathrm{~b}}$ \\
\hline 18 & +67.6 & 4.38 & 4.28 & 5.71 & 5.62 & 4.22 & 4.52 & 4.52 & 5.9 & 5.6 & 5.5 & 5.5 \\
\hline 11 & +147.8 & 4.52 & 4.29 & 5.69 & 4.87 & 4.55 & 4.54 & 4.30 & 0.5 & 3.3 & 4.1 & 7.7 \\
\hline $19^{c}$ & +60.0 & 4.37 & 4.29 & 5.71 & 5.55 & 4.20 & 4.41 & 4.41 & 5.4 & 5.7 & 5.4 & 5.4 \\
\hline $20^{c}$ & +83.5 & 4.79 & 3.98 & 5.69 & 4.84 & 4.45 & 4.39 & 3.96 & 1.0 & 3.0 & 4.0 & 2.0 \\
\hline
\end{tabular}

${ }^{a} \mathrm{CHCl}_{3}$ was used as a solvent. ${ }^{b}$ Benzene- $d_{6}$ was used as a solvent. ${ }^{c}$ These values were obtained from the literature. ${ }^{30}$

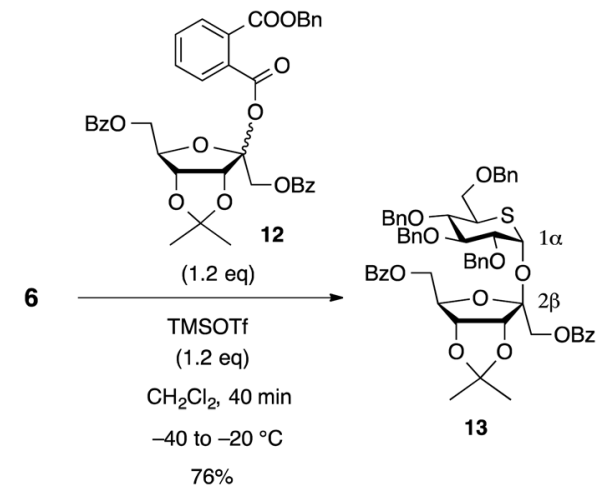

Scheme 4 Psicofuranosylation with 5-thio- $\alpha$-D-glucopyranose 6.

glycoside. In general, the $\mathrm{C} 2$-carbon of psicofuranoside appears between 107-109 ppm for $\beta$ anomers and between 103-105 ppm for $\alpha$ anomers, ${ }^{19,20}$ and the ${ }^{13} \mathrm{C}\left\{{ }^{1} \mathrm{H}\right\}$ NMR chemical shift of the anomeric carbon existed at $109.9 \mathrm{ppm}$ in $\mathbf{1 3}$.

In this reaction, protected 5 -thioglucose 6 performed an $\alpha$ directing acceptor as same as $\mathbf{9}$ in the synthesis of 5 -thioisosucrose. The glycosidation occurred on the $\beta$-face of the furanose donor $\mathbf{1 2}$ because of the steric influence of the acetonide group existing on the $\alpha$-side of the ring. Considering that D-psicofuranosylation of the corresponding $\alpha$-D-glucose gave a mixture in the ratio of $2: 1$ ( $\alpha$-glucopyranoside $v$ s. $\beta$ glucopyranoside) ${ }^{19}$ it should be noted that the predominant selectivity for 5-thio-D-glucopyranose 6 vs. D-glucopyranose is quite interesting in psicofuranosylation of 5-thiopyranose and pyranose donors. ${ }^{26}$

Conversion of $\beta$-D-psicofuranoside 13 to $\beta$-D-fructofuranoside 17 was carried out in four steps (Scheme 5):

Deprotection of acetonide group in $\mathbf{1 3}$ with $p$-toluenesulfonic acid in $\mathrm{MeOH}$ gave diol 14 in 57\% yield. Benzoate 15 was obtained from $\mathbf{1 4}$ via a stannylene intermediate. Treatment of $\mathbf{1 4}$ with $\mathrm{Bu}_{2} \mathrm{SnO}$ in $\mathrm{MeOH}$ at reflux temperature followed by benzoylation on the C-4 hydroxy group with benzoyl chloride gave 15 selectively. ${ }^{27}$ The Swern conditions will be a choice for oxidation of the secondary hydroxy group in the presence of cyclic sulfide. The secondary alcohol of $\mathbf{1 5}$ was oxidized smoothly to give ketone 16 in $81 \%$ yield. Then, reduction of the ketone 16 with $\mathrm{NaBH}_{4}$ occurred from the bottom of the furanose ring selectively to convert to $\beta$-D-fructofuranoside $\mathbf{1 7}$ in $89 \%$ yield. The direction of hydride attack in the reduction of 3ketone is controlled by the adjacent 2- $\beta$-glycosidic bond to give 2,3-syn-product. ${ }^{28}$ Removal of both O-benzoyl and O-benzyl groups in disaccharide $\mathbf{1 7}$ under the Birch conditions and

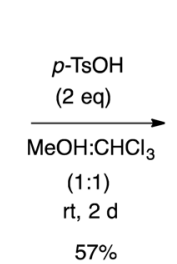

$57 \%$

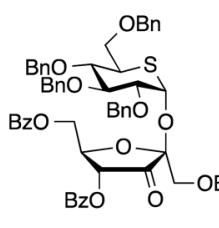

16

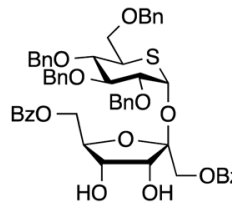

14

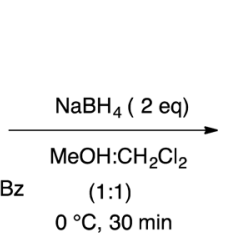

$89 \%$

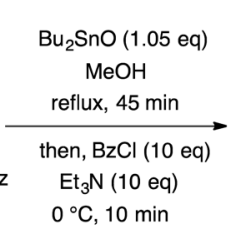

$62 \%$

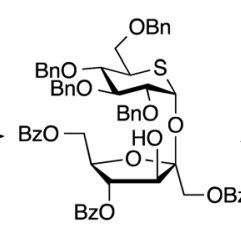

17

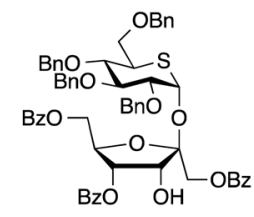

15

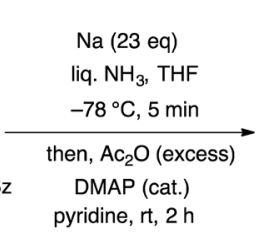

$87 \%$

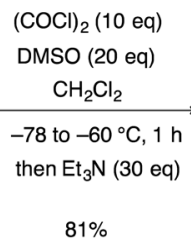

$(\mathrm{COCl})_{2}$ (10 eq)

DMSO (20 eq)

$\mathrm{CH}_{2} \mathrm{Cl}_{2}$

-78 to $-60^{\circ} \mathrm{C}, 1 \mathrm{~h}$

then $\mathrm{Et}_{3} \mathrm{~N}$ (30 eq)

$81 \%$
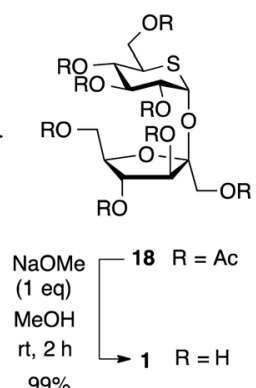

Scheme 5 Synthesis of 1. 

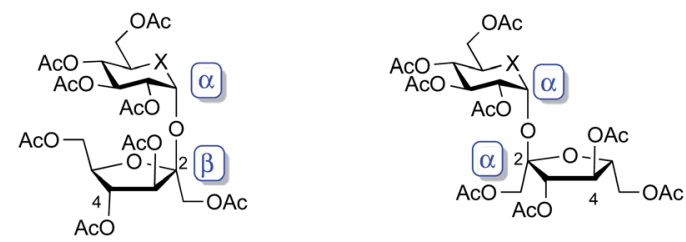

$\mathrm{X}=\mathrm{S} ; 18$

$\mathrm{X}=\mathrm{O}$; Sucrose octaacetate (19)

$\mathrm{X}=\mathrm{S} ; 11$

$\mathrm{X}=\mathrm{O}$; Isosucrose octaacetate $(\mathbf{2 0})$

Fig. 3 Octaacetate of 5-thiosucrose 18, 5-thioisososucrose 11, sucrose 19 , and isosucrose 20

successive acetylation gave octaacetate 18 in $87 \%$ yield. After deprotection of all acetyl groups under Zemplén's conditions, ${ }^{29}$ the synthesis of $\mathbf{1}$ was accomplished in $99 \%$ yield.

\section{Stereochemistry}

The specific rotations, and chemical shifts and coupling constant of ${ }^{1} \mathrm{H}$ NMR for octaacetates of 5-thiosucrose and 5thioisosucrose (18 and 11) are summarized with the corresponding data reported for sucrose and isosucrose $(\mathbf{1 9} \text { and } \mathbf{2 0})^{30}$ in Table 1. Their structures are shown in Fig. 3. Specific rotation values of 5-thioisosucrose and isosucrose (11 and 20) are relatively larger than those of 5-thiosucrose and sucrose (18 and $\mathbf{1 9})$. Chemical shifts of each $\alpha, \alpha$-anomers (11 and 20) and those of $\beta, \alpha$-anomers (18 and 19) are comparable in ${ }^{1} \mathrm{H}$ NMR. The chemical shifts of the $\mathrm{H}-4$ protons in furanose ring are characteristic. Their difference (ca. $0.7 \mathrm{ppm}$ ) can be observed between 19 and 20, and thioanalogs 18 and 11. Coupling constants of $J_{3,4}$ and $J_{4,5}$ in sucrose 19 and thiosucorse 18 are larger than those of isosucrose 20 and thioisosucorse 11. Thus, all these results supported the structures of 5-thiodisaccharides 11 and 18.

\section{Biological study}

Inhibitory activities against $\alpha$-glycosidase for compounds $\mathbf{1}, \mathbf{2}$, and 5-thio-D-glucose were examined in vitro using rat intestinal $\alpha$-glucosidase. In literature, 5-thio-D-glucose is reported to be a weak to moderate inhibitor for $\alpha$-glucosidase. ${ }^{11 f, 12}$ In the present study, 5-thio-D-glucose showed $48 \%$ inhibition at $8 \mathrm{mM}$. It was regrettable that neither $\mathbf{1}$ nor $\mathbf{2}$ exhibited any inhibition at $8 \mathrm{mM}$, while commonly used $\alpha$-glucosidase inhibitor such as acarbose and voglibose work at nM levels. Although 5-thio-Dglucose has a sweet taste, $\mathbf{1}$ was found to be a little bitter rather than sweet, in rough-and-ready taste analyses.

\section{Conclusions}

The first stereoselective syntheses of $\mathbf{1}$ and $\mathbf{2}$ were achieved by stereoselective glycosidation. The key steps involved D-fructofuranosylation and D-psicofuranosylation of protected 5-thio-Dglucose acceptors 9 and 6 to afford $\alpha$-D-fructofuranosyl 5-thio- $\alpha$ D-glucopyranoside 10 and $\beta$-D-psicofuranosyl 5-thio- $\alpha$-D-glucopyranoside 13 with high stereoselectivity in excellent yields, respectively. The configurations of their two-anomeric centers were strictly controlled in a single glycosidation step, in which the strong anomeric effect of 5-thio-D-glucopyranose was observed. We have demonstrated that 5-thio-D-glucopyranose works as an $\alpha$-directing glycosyl acceptor for the first time. Although neither 1 nor 2 exhibit $\alpha$-glucosidase inhibitory activity or sweetness, current results will aid in the design of new $\alpha$-glucosidase inhibitors and the synthesis of other disaccharide of thiosugar derivatives.

\section{Conflicts of interest}

There are no conflicts to declare.

\section{Acknowledgements}

We thank professor Hisashi Matsuda and professor emeritus Masayuki Yoshikawa of Kyoto Pharmaceutical University to guide our experiments in $\alpha$-glucosidase assay.

\section{Notes and references}

1 (a) M. R. Jenner, Sucralose: unveiling its properties and applications, in Progress in Sweeteners, ed. T. H. Grenby, Elsevier Applied Science, London, U.K., 1989, pp. 121-141; (b) V. L. Grotz, S. Molinary, R. C. Peterson, M. E. Quinlan and R. Reo, Sucralose, in Alternative Sweetners, ed. L. O'Brien-Nabors, CRC Press, Boca Raton, FL, 4th edn, 2006, pp. 181-196.

2 (a) L. Hough and K. S. Mufti, Carbohydr. Res., 1973, 29, 291; (b) I. D. Jenkins and S. Thang, Aust. J. Chem., 1984, 37, 1925; (c) C. Simiand, E. Samain, O. R. Martin and H. Driguez, Carbohydr. Res., 1995, 267, 1; (d) F. W. Lichtenthaler and S. Mondel, Carbohydr. Res., 1997, 303, 293.

3 (a) U. C. Dyer and Y. Kishi, J. Org. Chem., 1988, 53, 3383; (b) D. J. O'Leary and Y. Kishi, J. Org. Chem., 1993, 58, 304; (c) B. López-Méndez, C. Jia, Y. Zhang, L.-H. Zhang, P. Sinaÿ, J. Jiménez-Barbero and M. Sollogoub, Chem.-Asian J., 2008, $3,51$.

4 R. J. Capon and J. K. MacLeod, J. Chem. Soc., Chem. Commun., 1987, 1200.

5 (a) M. Yoshikawa, T. Murakami, H. Shimada, H. Matsuda, J. Yamahara, G. Tanabe and O. Muraoka, Tetrahedron Lett., 1997, 38, 8367; (b) M. Yoshikawa, T. Murakami, K. Yashiro and H. Matsuda, Chem. Pharm. Bull., 1998, 46, 1339; (c) M. Yoshikawa, T. Morikawa, H. Matsuda, G. Tanabe and O. Muraoka, Bioorg. Med. Chem., 2002, 10, 1547; (d) O. Muraoka, K. Yoshikai, H. Takahashi, T. Minematsu, G. Lu, G. Tanabe, T. Wang, H. Matsuda and M. Yoshikawa, Bioorg. Med. Chem., 2006, 14, 500.

6 (a) J. G. Fernandez-Bolaños, N. A. L. Al-Masoudi and I. Maya, Adv. Carbohydr. Chem. Biochem., 2001, 57, 21; (b) M. Sakono, A. Seko, Y. Takeda, M. Hachisu, A. Koizumi, K. Fujikawa, H. Seto and Y. Ito, $R S C A d v$., 2016, 6, 76879; 5-thioglucose; (c) M. S. Feather and R. L. Whistler, Tetrahedron Lett., 1962, 15, 667; (d) N. A. Hughes, J. Chem. Soc., Chem. Commun., 1979, 319; (e) H. Yuasa, J. Tamura and H. Hashimoto, J. Chem. Soc., Perkin Trans. 1, 1990, 2763; (f) H. Driguez and 
B. Henrissat, Tetrahedron Lett., 1981, 22, 5061; $(g)$ J. Uenishi and H. Ohmiya, Tetrahedron, 2003, 59, 7011; 5-thiogalactose; (h) J. E. N. Shin and A. S. Perlin, Carbohydr. Res., 1979, 76, 165; 5-thiomannose; (i) H. Yuasa, Y. Izukawa and H. Hashimoto, J. Carbohydr. Chem., 1989, 8, 753.

7 (a) H. J. M. Gijsen, L. Qiao, W. Fitz and C.-H. Wong, Chem. Rev., 1996, 96, 443; (b) V. H. Lillelund, H. H. Jensen, X. Liang and M. Bols, Chem. Rev., 2002, 102, 515; 5azaglucose (nojirimycin); (c) S. Inoue, T. Tsuruoka, T. Iyo and T. Niida, Tetrahedron, 1968, 24, 2125.

8 (a) T. Suami and S. Ogawa, Adv. Carbohydr. Chem. Biochem., 1990, 48, 21; (b) O. Arjona, A. M. Gómez, L. J. Cristóbal and J. Plumet, Chem. Rev., 2007, 107, 1919; voglibose; (c) S. Horii, H. Fukase, T. Matsuo, Y. Kameda, N. Asano and K. Matsui, J. Med. Chem., 1986, 29, 1038.

9 (a) S. Mehta and B. M. Pinto, Tetrahedron Lett., 1992, 33, 7675; (b) H. Yuasa, O. Hindsgaul and M. M. Palcic, J. Am. Chem. Soc., 1992, 114, 5891; (c) S. Mehta, K. L. Jordan, T. Weimar, U. C. Kreis, R. J. Batchelor, F. W. B. Winstein and B. M. Pinto, Tetrahedron: Asymmetry, 1994, 5, 2367; (d) H. Hashimoto, M. Kawanishi and H. Yuasa, Chem.-Eur. J., 1996, 2, 556; (e) B. D. Johnston and B. M. Pinto, J. Org. Chem., 1998, 63, 5797; (f) Y. Morii, H. Matsuda, K. Ohara, M. Hashimoto, K. Miyairi and T. Okuno, Bioorg. Med. Chem., 2005, 13, 5113.

10 C.-H. Wong, Y. Ichikawa, T. Krach, C. G.-L. Narvor, D. P. Dumas and G. C. Look, J. Am. Chem. Soc., 1991, 113, 8137.

11 (a) D. J. Hoffman and R. L. Whistler, Biochemistry, 1968, 7, 4479; (b) R. L. Whistler and W. C. Lake, Biochem. J., 1972, 130, 919; (c) B. Hellman, А. Lernmark, J. Sehlin, I.-B. Täljedal and R. L. Whistler, Biochem. Pharmacol., 1973, 22, 29; (d) J. R. Zysk, A. A. Bushway, R. L. Whistler and W. W. Carlton, J. Reprod. Fertil., 1975, 45, 69; (e) J. H. Kim, S. H. Kim, E. W. Hahn and C. W. Song, Science, 1978, 200, 206; (f) Y. L. Merrer, M. Fuzier, I. Dosbaa, M.-J. Foglietti and J.-C. Depezay, Tetrahedron, 1997, 53, 16731.

12 T. Kajimoto, K. K.-C. Liu, R. L. Pederson, Z. Zhong, Y. Ichikawa, J. A. Porco Jr and C.-H. Wong, J. Am. Chem. Soc., 1991, 113, 6187.

13 (a) S. Chiba, Biosci., Biotechnol., Biochem., 1997, 61, 1233; (b) E. B. de Melo, A. S. Gomes and I. Carvalho, Tetrahedron, 2006, 62, 10277.

14 (a) P. Fügedi, Glycosylation methods, in The Organic Chemistry of Sugars, ed. D. E. Levy and P. Fügedi, CRC Press, Boca Raton, FL, 2006; (b) Handbook of Chemical Glycosylation, ed. A. V. Demchenko, WILEY-VCH, Weinheim, Germany, 2008.

15 (a) R. U. Lemieux and G. Huber, J. Am. Chem. Soc., 1953, 75, 4118; (b) R. U. Lemieux and G. Huber, J. Am. Chem. Soc., 1956, 78, 4117; (c) H. Tsuchida and M. Komoto, Agric. Biol. Chem., 1965, 29, 239; (d) R. K. Ness and H. G. Fletcher Jr,
Carbohydr. Res., 1971, 17, 465; (e) D. E. Iley and B. FraserReid, J. Am. Chem. Soc., 1975, 97, 2563; $(f)$ B. Fraser-Reid and D. E. Iley, Can. J. Chem., 1979, 57, 645.

16 (a) A. Klemer, K. Gaupp and E. Buhe, Tetrahedron Lett., 1969, 52, 4585; (b) A. Bouali, G. Descotes, D. F. Ewing, A. Grouiller, J. Lefkidou, A.-D. Lespinasse and G. Mackenzie, J. Carbohydr. Chem., 1992, 11, 159; (c) T. Müller, R. Schneider and R. R. Schmidt, Tetrahedron Lett., 1994, 35, 4763; (d) Y.-L. Li and Y.-L. Wu, Tetrahedron Lett., 1996, 37, 7413; (e) T. Yamanoi, N. Misawa and M. Watanabe, Tetrahedron Lett., 2007, 48, 6458; (f) G. Lian, Q. Gao and F. Lin, Carbohydr. Res., 2008, 343, 2992.

17 (a) S. Oscarson and F. W. Sehgelmeble, J. Am. Chem. Soc., 2000, 122, 8869; (b) S. Oscarson and F. W. Sehgelmeble, J. Org. Chem., 2002, 67, 8457; (c) S. Oscarson and F. W. Sehgelmeble, Tetrahedron: Asymmetry, 2005, 16, 121.

18 An $\alpha$-anomer exists predominantly $(\alpha: \beta=>10: 1)$ in 6 and 9.

19 J. Uenishi and A. Ueda, Tetrahedron: Asymmetry, 2008, 19, 2210.

20 Other examples of $\beta$-D-psicofuranosylations; (a) J. Uenishi and A. Ueda, Heterocycles, 2009, 77, 1297; (b) A. Ueda, T. Yamashita and J. Uenishi, Carbohydr. Res., 2010, 345, 1722; (c) A. Ueda, Y. Nishimura, Y. Makura, M. Tanaka and J. Uenishi, Heterocycles, 2018, 97, 729.

21 A. Ueda, T. Yamashita and J. Uenishi, Heterocycles, 2010, 81, 1711.

22 R. R. Schmidt and J. Michel, Angew. Chem., Int. Ed. Engl,, 1980, 19, 731.

23 K. S. Kim, Y. J. Lee, H. Y. Kim, S. S. Kang and S. Y. Kwon, Org. Biomol. Chem., 2004, 2, 2408.

24 A mixture of $\alpha$ - and $\beta$-anomers; for $8 \mathbf{d}(\alpha: \beta=1: 1.2)$ and for $12(\alpha: \beta=1: 15)$.

25 S. J. Angyal and G. S. Bethell, Aust. J. Chem., 1976, 29, 1249. 26 The similar results were observed in the case of $\mathrm{D}^{-}$ glucopyranosylation of $\mathrm{D}$-fructofuranose as well as $\mathrm{D}^{-}$ tagatofuranose. The glycosylation of 4 with $\mathrm{D}^{-}$ fructofuranose $\mathbf{8 c}$ gave a mixture of pyranosides, $\alpha$-D-Fru $f$ $(2 \leftrightarrow 1)-\alpha$-D-Glcp and $\alpha$-D-Fruf- $(2 \leftrightarrow 1)-\beta$-D-Glcp, in a $5: 4$ ratio. Y. Makura, A. Ueda, T. Matsuzaki, T. Minamino and M. Tanaka, Tetrahedron, 2019, 75, 3758.

27 D. Wagner, J. P. H. Verheyden and J. G. Moffatt, J. Org. Chem., 1974, 39, 24.

28 (a) A. Földesi, T. V. Maltseva, Z. Dinya and J. Chattopadhyaya, Tetrahedron, 1998, 54, 14487; (b) A. Földesi, A. Trifonova, Z. Dinya and J. Chattopadhyaya, J. Org. Chem., 2001, 66, 6560.

29 G. Zemplén and E. Pacsu, Ber. Dtsch. Chem. Ges., 1929, 62, 1613.

30 G. R. Newkome, J. D. Sauer, V. K. Majestic, N. S. Bhacca, H. D. Braymer and J. D. Wander, Carbohydr. Res., 1976, 48, 1. 